\title{
The impact of terrorist attack news on moral intuitions and outgroup prejudice
}

Tamborini, Ronald ; Hofer, Matthias ; Prabhu, Sujay ; Grall, Clare ; Novotny, Eric Robert ; Hahn, Lindsay ; Klebig, Brian

\begin{abstract}
Using logic suggested by the model of intuitive morality and exemplars, we examined the impact of exposure to terrorist attack news coverage on the salience of moral intuitions and prosocial behavioral intentions toward outgroup members. In an experiment, participants were randomly assigned to watch news of the 2015 Paris terrorist attacks or a control news story. Afterward, we measured the salience of five moral intuitions (sensitivity to care, fairness, loyalty, authority, and purity) and the participants' prejudice (i.e., the lack of intentions to help outgroup members). Results showed that exposure to terrorist attack news (a) increased the salience of respect for authority and subsequently (b) reduced prosocial behavioral intentions toward outgroup members. Closer inspection revealed that authority salience mediated the effect of terrorist news exposure on these behavioral intentions toward outgroup members. In a second study using the same design as in the first study, we ensured that the ingroup and the outgroup addressed in the first study were indeed perceived differently on dimensions of ingroup membership.
\end{abstract}

DOI: https://doi.org/10.1080/15205436.2017.1342130

Posted at the Zurich Open Repository and Archive, University of Zurich

ZORA URL: https://doi.org/10.5167/uzh-145355

Journal Article

Accepted Version

Originally published at:

Tamborini, Ronald; Hofer, Matthias; Prabhu, Sujay; Grall, Clare; Novotny, Eric Robert; Hahn, Lindsay; Klebig, Brian (2017). The impact of terrorist attack news on moral intuitions and outgroup prejudice. Mass Communication and Society, 20(6):800-824.

DOI: https://doi.org/10.1080/15205436.2017.1342130 


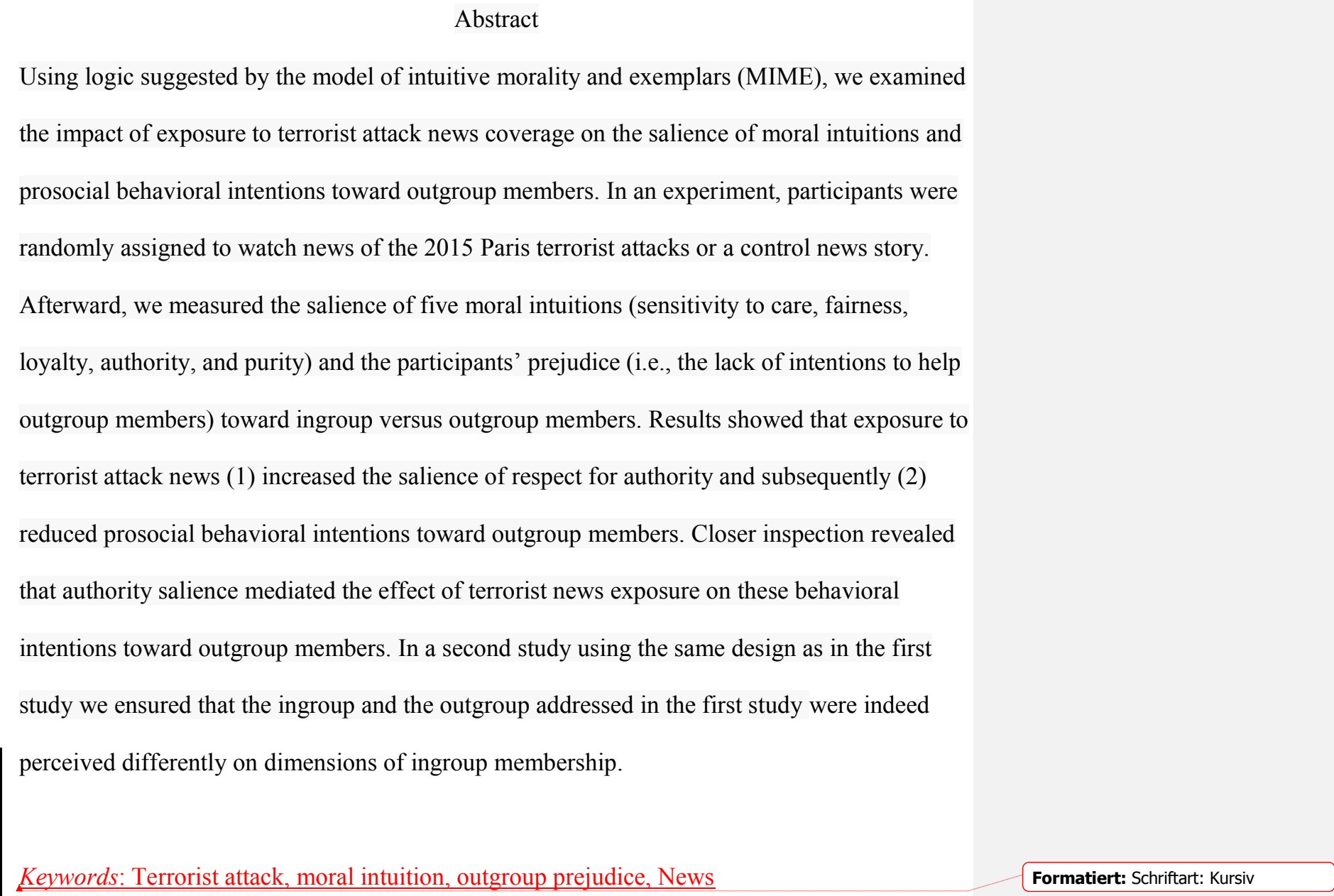


The Impact of Terrorist Attack News on Moral Intuitions and Outgroup Prejudice

On the evening of November 13, 2015, a series of coordinated terrorist attacks took place in Paris. The attacks began at 9:20pm local time and consisted of several suicide bombings and mass shootings. At least 126 civilians were killed and 389 were injured. A terrorist group known as Islamic State (commonly referred to as ISIS) claimed responsibility for these attacks. ISIS declared the attacks as a response to French airstrikes against ISIS's militants in Syria. This marked the deadliest attack on the nation of France since World War II (Alderman \& Ardley, 2015).

Terrorist attacks like those in Paris are not only a national tragedy, but create an international crisis when they are perceived to threaten the core values that underlie society (Mogensen, 2008). Accordingly, such attacks typically receive extensive media coverage worldwide, and increase the public's media use during and after such crises (Althaus, 2002). Media coverage associated with terrorist attacks can dramatically change public opinion and attitudes, as such attacks "manifest themselves in the minds of people as a threat to personal and national security" (Boomgaarden \& De Vreese, 2007, p. 355; see also Traugott et al., 2002).

In particular, exposure to terrorist news has been shown to worsen attitudes toward outgroup members who are perceived to be associated with the attacks. For example, research has shown that exposure to news about Dutch filmmaker Theo Van Gogh's murder by Islamic terrorists ultimately increased antisocial attitudes toward Muslims (Das, Bushman, Bezemer, Kerkhof, \& Vermeulen, 2009). Similar research showed higher anti-Arabic prejudices after the 2004 Madrid train bombings (Echebarria-Echabe \& Fernández-Guede, 2006). A spike in antiIslamic hate crimes in the United States after 9/11 suggests that such prejudice is not restricted to attitudes, but extends to behavior as well (Byers \& Jones, 2007).

Although prior research has been useful in identifying the effects of terrorist attacks on explicit attitudes such as outgroup prejudice, little is known about the cognitive processes that 
can facilitate these outcomes (but see Das et al., 2009). Concern with media's ability to influence social attitudes, stereotypes, and prejudicial behavior have dominated the attention of media researchers and social critics alike, but without an understanding of the cognitive mechanisms that govern these outcomes, we have little chance of solving their related social problems. We argue that the influence of terrorist news exposure on explicit attitudes and prejudices is mediated by the accessibility of moral intuitions (i.e., gut instinct mechanisms related to judgments of morality). More specifically, in the present study we apply the mediating processes outlined in the model of intuitive morality and exemplars (MIME, Tamborini, 2011, 2013) to argue that news coverage of the 2015 Paris terrorist attacks can affect the salience of evolutionarily developed group-centric moral intuitions that, in turn, decrease prosocial behavioral intentions toward outgroup members. We interpret this decrease in prosocial intentions towards outgroup members as an indicator of outgroup bias. In addition, we explore how these effects might be a function of the concreteness of news stories.

\section{The MIME}

The MIME offers a framework for extending traditional approaches to media effects research to increase understanding of the manner in which terrorist attack news can impact social perceptions and outgroup prejudice. Models that outline the relationship between media exposure and social behavior are abundant; however, the MIME is distinguished by its focus on the role of moral intuitions. More specifically, the MIME suggests that media content can influence evolutionarily developed moral instincts (known as moral intuitions) in audience members and outlines the short-term and long-term processes through which moral judgment occurs as a function of these instincts/intuitions. According to the MIME, in the short term, exposure to morally relevant environmental cues (including media exemplars) can increase the temporary salience (i.e., accessibility) of related intuitions. Once activated, these moral intuitions can impact attitudes, decision making, and subsequent behavior. The MIME proposes that in the long term, repeated exposure to morally relevant media content can make the 
respective intuitions chronically salient and, through this mechanism, affect enduring behavior. The MIME combines exemplification theory (Zillmann, 2002) and moral foundations theory (MFT; Haidt \& Joseph, 2007) to make specific predictions about how media exemplars activate individual moral intuitions.

Moral intuitions. The MIME draws moral intuitions from MFT, which describes these instincts as communally beneficial "bits of mental structure" (Haidt \& Joseph, 2007, p. 381) that cause instinctive, gut reactions of right/wrong in response to specific actions or behaviors. MFT contends that these intuitions have developed over thousands of years through the course of evolution and have aided the survival of human beings. Unlike accounts that define moral judgment as a product of rational cognitive processes (e.g., Kohlberg, Levine, \& Hewer, 1983), MFT regards moral judgment as the result of intuitive affect. Proponents of the theory argue that judgments are most often driven by moral intuition, which form the foundation for and automatically guide gut determinations of right or wrong without the need for deliberative thinking (Haidt \& Joseph, 2007).

MFT identifies five of these intuitions, each associated with a sensitivity to a specific domain of social behavior: (1) care is based on sensitivity to the suffering of others and the resulting empathic responses; (2) fairness pertains to principles related to reciprocity, such as equal treatment or equitable distribution of resources; (3) ingroup loyalty deals with commitment and favoritism toward ingroup members; (4) authority is related to respect for and deference to traditions and hierarchies; and (5) purity is concerned with noble living and disgust mechanisms.

Research by Graham et al. (2011) shows that these five moral intuitions can be combined into two higher order concepts. That is, care and fairness represent so-called individualizing intuitions (associated with concern for the well-being of other individuals), whereas loyalty, authority, and purity represent so-called binding intuitions (associated with concern for community well-being). The salience of individualizing intuitions has been 
associated with liberal values, whereas the salience of binding intuitions has been associated with conservative values and attitudes (Graham, Haidt, \& Nosek, 2009; Van Leewuen \& Park, 2009). We argue that these intuitions act as mediators through which terrorist news exposure impacts prejudice toward outgroup members.

\section{Effect of News on Terrorist Attacks on Outgroup Prejudice}

Prior investigations examining the influence of terrorist attack news have focused on how coverage can affect prejudice toward outgroup members (Das et al., 2009; EchebarriaEchabe \& Fernández-Guede, 2006). However, this research has either not examined any mediating variables or focused on a narrow range of mediating mechanisms responsible for such change. For instance, Das et al. (2009) proposed the mediating mechanisms described in terror management theory (TMT; Greenberg, Pyszczynski, \& Solomon, 1986) to explain the influence of terrorist news on outgroup prejudice. More specifically, this research reasoned that terrorist news exposure increased death-related thoughts, which made people sublimate mortality by defending their enduring cultural worldviews. In doing so, TMT explains, people become suspicious of any who pose a threat to these worldviews.

However, there are limits to TMT. For instance, although terror management theory is a useful framework for investigating the effects of terrorist news on outgroup prejudice (Das et al., 2009), the cognitive mechanisms that mediate the effect of terrorist news on these outcomes have been overlooked in most research or difficult to interpret when they have been examined (e.g., Das et al. 2009). Other studies generally claim that fear or anxiety about death (hence the term anxiety buffer) is the mechanism mediating the outcomes (see Burke et al. 2010, pp. 159176); however, these studies refrain from measuring fear of death. This intentional omission makes sense. The scale itself would be a reminder of death and, as such, would make a true control condition impossible.

In the context of terrorist news, terror management theory would explicate how terrorist news sparks death-related thoughts in media users, which in turn lead to defense of cultural 
worldviews (manifested as outgroup prejudice in this case). While it is plausible that deathrelated thoughts can lead to outgroup prejudice, we do not believe that this is the only factor that can contribute to outgroup prejudice. In this paper, we outline a completely different psychological mechanism (independent of the cognitive mechanism outlined in TMT) through which terrorist news can affect prejudice towards outgroups. We have attempted to explain how these instincts can lead to the spontaneous activation of outgroup prejudice, which do not involve personal fear of death per se.

Whereas TMT research provides evidence of outcomes stemming from an individual's fear of his/her own death (e.g., Florian \& Mikulincer, 1997), it is less applicable to outcomes driven by threat to others. One could argue that terrorist news, especially when involving a terrorist attack in another country, evokes thoughts of threats to other people and the social order more than thoughts of one's own death, as mortality salience evokes. Therefore, a theory that explains the influence of terrorist news on mechanisms associated with societal outcomes would be more applicable. Instead of TMT we use the MIME, which combines exemplification theory and MFT to predict the effect of terrorist news on the accessibility of binding moral intuitions and subsequent outgroup bias.

While recognizing that fear of death or other intuitions related to the self may play a role in determining news of terrorist attacks effects outgroup prejudice, we contend that the group-related binding intuitions, which MFT describes as being present in all human beings from birth, are a) sensitive to media stimuli which can provoke a sense of threat to the group, and b) capable of influencing subsequent attitudinal and behavioral outcomes. Thus, this study is intended to test if the binding intuitions can serve as mediators of the influence of terroristrelated news on outgroup bias. Notably, previous research has been limited to examining how terrorist attack news affects attitudinal responses such as hatred of outgroup members, without addressing its impact on behavioral intentions. The present study extends this research to examine the effects of terrorist news coverage on prosocial behavioral intentions toward 
outgroup members (indicating benevolent concern) or the lack thereof (indicating malevolent, antisocial prejudice).

\section{Hypothesized Model}

The study's central hypothesis predicts that the salience of the binding intuitions will mediate the influence of exposure to terrorist attack news on prosocial behavioral intentions toward outgroups. More specifically, we hypothesize the following:

H1a: Exposure to news of the Paris terrorist attacks will increase the salience of binding intuitions of loyalty, authority, and purity.

Support for this logic can be found in work by Van Leeuwen and Park (2009) who showed that the impact of perceptions of social danger on conservative attitudes was mediated by the salience of binding intuitions. In showing this mediation, they established a causal link between fear and the activation of the binding intuitions. They explained that binding intuitions offered "protection" (p. 170) against threat, presumably because humans have benefited from group affiliation when their survival is threatened. Given that these moral intuitions are described as evolutionarily developed instincts, it is reasonable to believe that natural selection has favored the development of instincts that bind an individual to his/her group in the face of threats, with one modern manifestation being terrorist attacks.

This evolutionary account is explained more thoroughly by Van Leeuwen, Park, Koenig, and Graham (2012), who showed that pathogen prevalence in countries strongly predicted the salience of the three binding intuitions for people living in these countries. They specifically discuss how pathogen contamination poses a threat to survival, and how human beings with strong group-related instincts sensitive to threat may have been more likely to survive and pass on those instincts to future generations. More specifically, commitment and bonding with fellow ingroup members can offer protection from dangerous outside threats, so it is quite likely that natural selection favored humans whose ingroup loyalty intuition was immediately activated upon perceived threat. In addition, adherence to traditions and taking 
orders (authority) in response to threat, and disgust mechanisms that can make people wary of foreign and potentially harmful objects (purity) in the face of threat have evolutionary advantages that likely made the authority and purity intuitions sensitive to threat over the course of human history.

In the context of modern times, it is arguable that few events can stimulate the primordial sense of threat to survival as a terrorist attack can (Boomgaarden \& De Vreese, 2007). Hence, we could expect that exposure to mediated threat in the form of terrorist attack news should innately activate the three binding intuitions in human beings. Previous research on the effects of TV news exposure on binding intuitions supports this prediction. For instance, exposure to news content focusing on nuclear threat was found to increase the salience of authority without influencing other intuitions (Tamborini, Prabhu, Hahn, Idzik, \& Wang, 2014; Tamborini, Prabhu, Wang, \& Grizzard, 2013).

Although MIME research has not yet explored the role of binding intuitions on behavioral outcomes, there is reason to believe that all three binding intuitions can influence responses to outgroup members. The mechanisms that underlie the binding intuitions not only lead humans to put communal needs above their own, but also to increase bias toward noncommunity members in times of threat (Kugler, Jost, \& Noorbaloochi, 2014). Extending Haidt and Joseph (2007), we argue that activation of the ingroup loyalty intuition can lead to higher levels of commitment to one's ingroup, which might inhibit active participation with outgroups. The authority intuition, once primed, increases the salience of rules that protect the group including preferential treatment of ingroup over outgroup members, and submission to authoritative rules that may protect from outgroup members. Finally, the increased accessibility of the purity intuition can lead to disgust and avoidance responses directed toward outgroup members who might represent physical and spiritual contamination.

In line with the logic of the MIME, we predict the following: 
H1b: The salience of binding intuitions will decrease prosocial behavioral intentions toward outgroup members (which we consider an increase in prejudice toward outgroup members).

Finally, our third hypothesis (H1c) represents the mediation (by binding intuition salience) of the effect of exposure to terrorist attack news on prosocial behavioral intentions toward outgroup members.

H1c: Binding intuitions mediate the effect of exposure to terrorist attack news on prosocial intentions toward outgroup members.

The MIME predicts that content features in media will prime intuition salience to influence decisions and related behaviors (Tamborini, 2013). Though previous research has separately examined paths $\mathrm{H} 1 \mathrm{a}$ and $\mathrm{H} 1 \mathrm{~b}$, to our knowledge no research to date has examined the mediation process $(\mathrm{H} 1 \mathrm{c})$ outlined in the MIME. All three hypotheses are represented in the research model in Figure 1. ${ }^{1}$

$<$ Figure $1>$

\section{The Importance of Exemplar Strength of Terrorist News Stories}

In addition to MFT, the MIME also draws on logic from exemplification theory (Zillmann, 2002) to explain how specific media content can exemplify moral principles, and hence serve as exemplars of moral intuitions. An exemplar is a prototypical example of some phenomenon that demonstrates the important aspects of that phenomenon. For instance, a media exemplar of the care intuition would be a video clip of the moment a mother feeds her hungry child (Tamborini, Prabhu, Grizzard, \& Eden, 2016). Such an exemplar would temporarily increase the accessibility of the care intuition in viewers. While considerable research demonstrates the importance of mere exposure to media exemplars as a determinant of media effects (e.g., Zillmann \& Brosius, 2000), less research has examined the role of the strength of a media exemplars, which relates to how concrete and emotion inducing the exemplar is. 
In the context of terrorism-related media, in several previous studies on terrorist news, outgroup prejudice has been attributed to simply being made aware of a potential attack (e.g., Boomgaarden \& De Vreese, 2007; Bozzoli \& Müller, 2011; Echebarria-Echabe \& FernándezGuede, 2006). We know of only one study that examines characteristics of exemplar strength in this context, in particular, the level of graphicness portrayed (Grizzard et al., 2015). We apply components of the MIME to more closely examine the possible effects of exemplar strength in terrorist news on intuition salience and subsequent outgroup prejudice.

As mentioned above, the MIME adopts exemplification logic to argue that a media exemplar's impact on judgment increases as the exemplar becomes stronger (i.e., more concrete and emotional; Zillmann, 2002). Support for this argument is widespread in research examining the effect of exemplification in news (Zillmann \& Brosius, 2000). Evidence for the effects of concrete exemplars can be found in other literatures. For example, McKinley and Fahmy (2011) showed that the level of graphicness (a characteristic tied to concreteness and emotionality) of images of the Israeli/Palestinian conflict affects viewers' emotional states. Grizzard et al. (2015) specifically examined the influence of graphicness in news footage of terrorist acts (i.e., an ISIS execution) on moral emotions and subsequent intuition salience. They found that the graphicness of the depiction of a mass shooting affected the experience of anger and disgust, which then increased the salience of moral intuitions. This leads to our second hypothesis (H2):

$\mathrm{H} 2$ : The positive influence of terrorist-news stories on the salience of binding intuitions is stronger when they are more concrete/emotional.

\section{Study 1}

\section{Method}

Participants. A total of 238 undergraduate students ${ }^{2}$ at a large university in the Midwestern United States participated in a between-subjects experiment $\left(n_{\text {female }}=158, M_{\text {age }}=\right.$ 20.04, $S D=1.67)$. All students in the sample received course credit for their participation. 
Participants were randomly assigned to one of three experimental conditions $\left(n_{\text {control }}=77, n_{\text {low }}\right.$ exemplar strength $=77, n_{\text {high exemplar strength }}=84$ ). The university's ethics review board approved all procedures. $^{3}$

Procedure. The study began two weeks after the 2015 Paris terrorist attacks and was completed within a week. To complete the study, participants sat in front of a 17-inch computer screen. After signing an online consent form, participants were randomly assigned to one of six experimental conditions in a $3 \times 2$ design that varied exposure to news of the Paris terrorist attacks (high exemplar strength, low exemplar strength, control) and target of prosocial behavioral intentions (ingroup vs. outgroup). Next, they completed measures assessing the salience of moral intuitions and prosocial behavior toward the target group. Participants were then debriefed and dismissed. The target of prosocial behavior was manipulated in order to determine whether the influence of intuition salience on prosocial behavioral intentions (H1b) varied as a function of the target of the prosocial behavioral intentions. More precisely, we expected intuition salience to affect prosocial behavioral intentions only for outgroup members.

Stimuli. News stories were drawn from various online sources. The TV reports were disguised as coming from the same network (CBS News). Participants in the control group saw video news stories about a restaurant and about a new method of electricity production using the kinetic energy of sea waves. In addition to the control group, we created two treatment conditions varying exemplar strength. Participants in the treatment groups saw the same two news stories seen by the control group, and a third story that was either (a) video footage of the Paris attacks with a voice-over (high exemplar strength) or (b) a video consisting of still images selected from the same video with the same voice-over (low exemplar strength). Both treatment conditions showing the Paris attacks depicted a timeline of events superimposed over a map of locations in the city where attacks took place, and interspersed recordings from surveillance cameras and private cell phones. For example, in the high exemplar condition, participants heard the newscaster describe a scene in which shattering glass flies across the screen, a 
gunman is seen approaching café patrons, chairs are being tossed, and people are seen diving for cover under tables, while seeing moving images of these events. In the low exemplar condition, participants heard the same description while seeing still shots of shattered glass, the gunman, overturned chairs, and people crouched under tables.

The use of videos versus still images is expected to vary exemplar strength both in terms of perceived concreteness and emotionality. Concreteness is expected to be higher in the video condition because participants could see all the character and object movements that the newscaster was describing verbally. Emotionality is expected to be higher in the video condition because of its structural features. Previous research on structural features shows that motion in media stimuli increases both the self-reported emotionality of the media content as well as physiological arousal in respondents (Simons, Detenber, Roedema, \& Reiss, 1999). For example, things like zooms, pans, and other forms of camera action as well as action within a shot can increase arousal. This increase in arousal, in association with the content of terrorist attacks, is expected to heighten the perceived emotionality of the video.

\section{Measures}

Moral intuition salience. The salience of five moral intuitions was measured by items the moral foundations questionnaire (MFQ; Graham et al., 2011). The MFQ consists of 30 questions with six items for each moral intuition. More precisely, each moral intuition is assessed by three relevance statements (each statement beginning with: "When you decide whether something is right or wrong, to what extent are the following considerations relevant to your thinking?") and three judgment statements (each statement beginning with: "Please read the following sentences and indicate your agreement or disagreement."). Participants indicated their agreement and disagreement on a 7-point Likert scale. The anchors for the relevance scales were $1=$ Not at all relevant and $7=$ Extremely relevant . The anchors for the judgments were $1=$ Strongly disagree and $7=$ Strongly agree . 
Prosocial behavioral intentions. The intention to donate measure contained a target manipulation (ingroup vs. outgroup). That is, participants were first asked whether they would be willing to increase their tuition fees the following semester to support a program seeking to eliminate childhood hunger either in the Middle East (target: outgroup, $n=120$ ) or in the U.S. (target: ingroup, $n=118$ ). If they did not agree, they were coded as $\$ 0$. If they agreed, they were asked whether they would be willing to have between $\$ 1$ and $\$ 10$ added to their tuition the following semester. The range of $\$ 1$ to $\$ 10$ was selected based on consideration of the typically limited finances of college students. The means and standard deviations of both the MFQ and the donation amounts are presented in Table 1, along with their zero-order correlations.

Manipulation check. Finally, to examine whether the exemplar strength manipulation was successful we asked participants how concrete the events in the videos seemed to them ("How clear and concrete did the events in the video seem to you?"). The concreteness measure used a 7-point scale offering itemized responses that varied along a continuum from $1=s o$ unclear it was incomprehensible to $7=$ so clear it was like you were there $(M=5.51, S D=$ 0.93). We also asked participants how emotional they perceived the events in the videos ("How emotional did the video scenes seem to you?"), which was a scale that ranged from $1=$ very unemotional to $7=$ very emotional $(M=4.65, S D=1.68)$.

$<$ Table 1 $>$

\section{Results}

To examine the success of our exemplar strength induction, we conducted two separate one-way ANOVAs on items asking participants to evaluate the emotionality and concreteness of the terrorist news videos. The ANOVA examining emotionality showed a significant overall-effect of the induction on perceived emotionality: $F(2,235)=72.00, p<.001, \eta_{\mathrm{p}}{ }^{2}=$ 38. A post-hoc Scheffé test revealed that participants in the control condition showed significantly lower values on the emotionality measure $(M=3.16, S D=1.33)$ than both 
participants in the low $(M=5.35, S D=1.30)$ and high exemplar strength conditions $(M=$ $5.38, S D=1.36, p<.001)$. However, the low and high conditions did not differ significantly. In terms of perceived concreteness, we found a significant difference between the low $(M=$ $5.21, S D=1.15)$ and high concreteness $(M=5.62, S D=0.90, p=.01)$ conditions.

To examine our hypotheses and research questions we first conducted a multivariate analysis of variance (MANOVA) with the experimental factor (control vs. low vs. high exemplar strength) as the independent variable and the salience of the five moral intuitions as the dependent variables. This analysis revealed that the multivariate effect of the experimental manipulation on moral intuition salience approached significance: Wilks' $\Lambda=.93 F(10,462)=$ $1.73, p=.07, \eta_{\mathrm{p}}{ }^{2}=.04$

Post hoc analyses using the Scheffé post hoc criterion for significance indicated that there was no difference between the two exemplar strength conditions on moral intuitions. H2 was accordingly not supported. Because of this, and our observation that the exemplar strength conditions did not differ on emotionality, we collapsed the high and low exemplar strength conditions into a single experimental condition, called terrorist news exposure, for all subsequent analyses.

Follow-up analyses of variance (ANOVA) showed that only authority and purity salience differed between the experimental conditions. Specifically, we found that terrorist news exposure had a significant effect on the salience of authority, $F(2,235)=4.57, p<.05$, $\eta_{\mathrm{p}}{ }^{2}=.04$, and that the effect of terrorist news exposure on the salience of purity approached significance, $F(2,235)=2.89, p=.058, \eta_{\mathrm{p}}{ }^{2}=.02$. We found no effect of the terrorist news video on loyalty or the two individualizing intuitions, care and fairness (all $F<1$ ).

To test H1a we conducted analyses of variance examining the effect of terrorist news exposure on binding intuition salience (for authority, loyalty, and purity). The salience of authority was significantly lower in the control condition $(M=3.82, S D=.75)$ than in the terrorist news condition $(M=4.10, S D=.61), F(1,236)=8.84, p=\leq .01, \eta_{\mathrm{p}}{ }^{2}=.04$. The same 
pattern was found for purity, as the salience of this moral intuition was lower in the control condition $(M=3.46, S D=.84)$ than in the terrorist news condition $(M=3.75, S D=.88), F(1$, $236)=5.67, p=\leq .052, \eta_{\mathrm{p}}{ }^{2}=.02$. No significant effect was found for the salience of loyalty, $F$ $<1$. Therefore, H1a was partially supported by our data, as significant results were found for the salience of authority and purity, but not for loyalty.

To test $\mathrm{H} 1 \mathrm{~b}$ and $\mathrm{H} 1 \mathrm{c}$, we estimated three different moderated mediation models to examine the effects of the two moral intuitions that were affected by terrorist news exposure (authority and purity). For all three models, donation intention target (ingroup vs. outgroup) served as the moderator in order to determine whether the influence of intuition salience on prosocial behavioral intentions varied as a function of target-group membership. In the first model we tested for the mediational effect of purity and authority salience combined, and in the second and the third models we tested for the mediational effect of purity salience and authority salience separately.

To estimate these models, we used the PROCESS macro by Hayes (2013; model 15). Only the model with authority salience as the mediator yielded significant results (see Table 2). As can be seen from Table 2, terrorist news exposure had an effect on the authority intuition, such that participants who saw footage of the Paris attacks showed higher levels of authority salience than participants who saw the control videos $(b=0.27, S E=.09, p=.01)$. Authority intuition salience, in turn, negatively affected the amount participants were willing to donate ( $b$ $=-1.27, S E=.60, p=.03)$ and so did terrorist news exposure $(b=-2.21, S E=.84, p=.01)$. However, the effect of authority salience on intended donation amount was moderated by ingroup vs. outgroup $(b=-1.42, S E=.82, p=.08)$. That is, authority salience only affected donation intentions toward outgroup but not ingroup members (see Figure 3), which resulted in a moderated indirect effect. In other words, terrorist news exposure negatively affected prosocial behavioral intentions through authority salience but, as expected, only for the outgroup (i.e., a Middle Eastern organization against child hunger, $b=-0.34$, BootSE $=0.20$, 
BootCI $=-0.85$ to $-0.03 \underline{4}$ ). In terms of a US-organization, the indirect effect through authority salience was not significant $(b=0.04$, BootSE $=0.17$, BootCI $=-0.25$ to 0.43$)$.

$<$ Table 2>

$<$ Figure 3 $>$

\section{Study 1 Discussion}

The findings of the current study suggest that exposure to news of terrorist attacks has the capacity to activate authoritarian intuitions to a level that can lead to outgroup prejudice (i.e., a decrease in prosocial behavioral intentions toward an outgroup organization). They demonstrate that a single exposure to terror attack news can increase the temporary salience of the authority intuition and shape subsequent response toward outgroup members. The results show that exposure to news about the 2015 Paris terrorist attacks significantly increased the salience of some intuitions and not others. More precisely, exposure to news videos of these terrorist attacks increased the salience of two binding moral intuitions, namely authority and purity. The third binding intuition (loyalty) was not affected by exposure to these videos. This may have been due to the fact that loyalty as a concept pertains more to small groups (e.g., “tribes, gangs, and teams," Haidt \& Joseph, 2007, p. 17) rather than broad societies as a whole. Moreover, neither of the individualizing intuitions (care and fairness) was affected by the terrorist attack videos. In terms of the exemplar strength of the terrorist attack videos, our manipulation did not vary emotionality as expected and consequently, we did not find any effect of the exemplar strength induction (i.e., concreteness/emotionality) on moral intuition salience. However, perceived concreteness was affected by our exemplar strength induction.

Also, analyses revealed that media exposure had a significant effect on outgroup prejudice. We regarded a decrease in the willingness to donate to outgroup members as an indicator of outgroup prejudice. More precisely, exposure to terrorist attack news significantly decreased the amount of money viewers were willing to donate to an outgroup organization (i.e., a Middle Eastern organization against child hunger) if they were willing to donate at all. 
In line with our hypothesized model, this effect of terrorist news on donation intention was mediated by intuition salience. Notably, although terrorist news exposure increased the salience of both the authority and purity intuitions, tests showed that the mechanism mediating terrorist news exposure's effect on donation was the salience of authority. Purity did not serve as a mediator of this effect. Finally, the mediated effect of terrorist attack news on willingness to donate was not found for ingroup members.

Altogether, our findings show that exposure to terrorist news can ultimately affect viewers' outgroup prejudice. However, one might argue that in our study the terms outgroup and ingroup were not properly defined. In other words, we did not ensure whether the target donation group in our study - US children and Middle Eastern children - were perceived differently in terms of perceived ingroup membership. Therefore, we conducted an additional study.

\section{Study 2}

To address concerns that the target donation groups used in Study 1 (i.e., U.S. children and Middle Eastern children) were indeed perceived differently on dimensions of ingroup membership as expected, a second study was conducted. ${ }^{4}$ We hypothesized that participants would rate American targets higher than Middle Eastern targets on measures of perceived ingroup membership.

\section{Method}

Participants. Participants $\left(N=266, n_{\text {female }}=202, M_{\text {age }}=20.33, S D_{\text {age }}=2.10\right)$ were selected from the same population used in Study 1. Again, students in the sample received course credit for their participation, and the university's ethics review board approved all procedures.

Procedure. The second study duplicated the 3 x 2 design from Study 1 in order to determine the effect of our concreteness and donation target manipulations on a measure of perceived ingroup membership. Participants were randomly assigned to one of the same three 
experimental videos (control, low concreteness, and high concreteness) and were asked to contribute to one of two target groups (American or Middle Eastern organization against child hunger). Additional measures added specifically for Study 2 assessed the perceived ingroup membership of the target group to which they were assigned. As in Study 1, participants who viewed the low and high concreteness videos were combined into a single attack video condition.

Ingroup scale. All participants completed a perceived ingroup membership scale. The scale contained seven items measuring perceived ingroup membership on a Likert-type scale ranging from $1=$ strongly disagree to $7=$ strongly agree. Five of these items were adapted from Leach et al. (2008; e.g., "I feel a bond with [group]), and the remaining two were created specifically for this study (i.e., "I perceive [group] children as part of my ingroup," "I perceive hungry [group] children as part of my ingroup").

Respondents were asked to evaluate the perceived ingroup nature only for members of the donation target group to which they were assigned. For example, if you were assigned to the American children donation target group, the perceived ingroup membership scale asked only about perceptions of Americans. However, two different versions of the seven-item perceived ingroup membership scale were created for both the American and Middle Eastern children target groups in order to determine whether perceived ingroup membership would differ if the target was a child. Participants were randomly assigned to a version asking if they felt ingroup membership toward either (a) children from the assigned target group or (b) members of the assigned target group without specifying age. ANOVAs on perceptions of ingroup membership scale scores showed that age specification had no significant impact. As such, we combined data from participants who received versions of the scale that differed by age specification. This left us with a single measure evaluating perceived ingroup membership such that for participants assigned to the American children donation target group, our seven-item scale measured perceived ingroup membership toward Americans, 
whereas for participants assigned to the Middle Eastern children target group, our scale measured perceived ingroup membership toward Middle Easterners. The seven items were combined to form a single perceived ingroup membership scale $(M=4.63, S D=1.29, \alpha=$ $.83)$.

\section{Results}

A 2 (control video versus attack video) x 2 (Americans versus Middle Easterners) factorial ANOVA was conducted on perceived ingroup membership scale scores. A significant main effect was found for target group showing that U.S. targets $(M=5.32, S D=$ 1.07) were rated higher than Middle Eastern targets $(M=3.95, S D=1.10)$ on the perceived ingroup membership scale, $F(1,266)=110.95, p<.001, \eta_{\mathrm{p}}{ }^{2}=.30$. We found no significant effects for video condition or the interaction between video condition and target group (Fs > 1).

\section{Study 2 Discussion}

The findings are consistent with our prediction that participants would rate American targets higher on perceived ingroup membership than Middle Eastern targets. Because the mean for Middle Eastern targets was around the midpoint on our scale $(M=4.00)$, which represents neither agrees nor disagrees, participants considered Americans to be part of their ingroup, but not Middle Easterners. This is consistent with our contention that the measure of donation toward American versus Middle Eastern children's groups used in Study 1 was indicative of ingroup bias.

\section{General Discussion}

The outcomes of our investigation have several important implications. We focus on three of them in the following sections: First, our observation that the mediation of terrorist news exposure's impact on behavior occurred specifically through the authority intuition directs our attention to the importance of concepts related to authority for understanding outgroup bias. Second, our evidence for the short-term component of the MIME furthers 
support for the model's predictions that media exposure affects behavioral outcomes by activating moral intuitions. Third, our failure to find that exemplar strength affected the impact of media content on intuition salience or behavior directs our attention to components of the MIME based on exemplification theory.

\section{The Salience of the Authority Intuition and Outgroup Prejudice}

We began our investigation by considering the mediating influence of binding intuitions as a whole. Our expectation was that the salience of the binding intuitions would increase, as these intuitions have to do with the welfare of the group over and above the individual. The hypothesized effect of the media coverage of the 2015 Paris terror attacks on binding intuitions is consistent with previous research on the effects of terrorist attacks (Boomgaarden \& De Vreese, 2007; Bozzoli \& Müller, 2011; Echebarria-Echabe \& Fernández-Guede, 2006). Most interesting in this regard is our demonstration that news coverage of these attacks increased the salience of intuitive respect for authority. This effect is in line with prior research showing that exposure to terrorist attacks increased authoritarian attitudes (Bozzoli \& Müller, 2011;

Hetherington \& Suhay, 2011). However, unlike previous research that focuses on the impact of exposure to terrorism on explicit attitudes related to authority, the present study demonstrates that such videos can impact the foundational instincts (intuitions) upon which such attitudes may be based. In retrospect, however, it may come as little surprise that the salience of the authority intuition in particular proved to be the mechanism through which the decreases in prosocial behavioral intentions toward outgroup members occurred. Previous research has demonstrated that exposure to news of terrorist attacks can influence authoritarian beliefs (Echebarria-Echabe \& Fernández-Guede, 2006). Notably, while previous research links other binding intuitions with both knowledge of terrorist news attacks and outgroup bias, we do not find evidence for the mediating role of the other intuitions, whether binding or individualizing.

Notably, we did not observe any effect of the Paris terrorist attack news on the salience of ingroup loyalty. This lack of effect may be attributed to the measure we used: The loyalty 
subscale of MFQ (Graham et al., 2011). Although ingroup loyalty is conceptualized as both "recognizing, trusting, and cooperating with [ingroup] members" as well as "being wary and distrustful of members of other groups" (Haidt \& Graham, 2007, p. 105) items in the MFQ focus solely on the aspect pertaining to ingroup benefit such as "love our country," "loyalty to family," and being a "team player," while they ignore aspects pertaining to distrust of outgroup members. Indeed, previous research (Echebarria-Echabe \& Fernández-Guede, 2006) found that media content primarily influences the aspect of loyalty that pertains to outgroup distrust rather than ingroup loyalty. Although we do believe that both ingroup loyalty and outgroup distrust are different manifestations of the same underlying instinct, each may be more salient in different contexts. For example, listening to the national anthem is more likely to spark ingroup commitment, rather than outgroup mistrust. In the current study's context, given that these terrorist acts were committed by a hostile and seemingly maleficent outgroup, the terrorist attack news was more likely to provoke outgroup distrust, which may not have been properly captured in the items of the MFQ scale.

\section{Support for the MIME's Mediation Processes}

A central goal of our study was to test the mediation process outlined in the short-term component of the MIME. More precisely, media exemplars can act as primes to increase the salience of moral intuitions which then affect decision making. Support for this mechanism was provided in our test showing that the salience of the authority intuition mediated the negative influence of terrorist attack news on the willingness to donate to outgroup members. To our knowledge, this is the first time that the MIME's mediation process has been demonstrated empirically. Although previous research has demonstrated the ability of media exposure to increase the salience of moral intuitions (Grizzard et al., 2015; AUTHOR), and the ability of intuition salience to predict behavioral outcomes (AUTHOR), the results of the present investigation test and support the mediation process in its entirety. In doing so, the present findings not only support the logic underlying the MIME, but they also show the importance of 
understanding the role of moral intuition salience as a mechanism through which media can influence behavioral outcomes.

We began by expecting that all binding intuitions would mediate the influence of exposure to terrorist news attacks on prejudice. Instead we found that mediation occurred only through the authority intuition. In line with previous research showing the relationships between knowledge of terrorist attacks, authoritarian beliefs, and outgroup bias, the findings of this study suggest that the terrorist attack news created a desire for strong leadership in the face of threat, which led to the change in outgroup prejudice observed here. The implication is that media's impact on these basal instincts has wide-ranging consequences for behavioral outcomes. In this case, the increased salience of the authority intuition may have heightened a desire for authoritarian leadership and an acceptance of social hierarchies. The outcomes are in line with the MIME's predictions that media content does not just increase the salience of specific issues in the minds of audiences, but increases the salience of moral intuitions that, in turn, can influence a broad range and thoughts and behaviors.

If researchers can identify intuitions that can shape desired outcomes, message producers can design content better suited for bringing about desired change. For example, if content increases the salience of the authority intuition, which then decreases prosocial behavior toward outgroup members, perhaps content that decreases the salience of the authority intuition could increase prosocial behavior toward outgroup-members. There is still need for research identifying the types of message features that will increase or decrease the salience of intuitions related to specific behavioral outcomes. This research is likely to prove challenging; however, the implications of success in this area are considerable.

\section{The Importance of Exemplar Strength}

Exemplar strength was varied by a video condition and a still-image condition, but had no influence on any intuition. This is inconsistent with previous research that has shown an effect of concrete/graphic exemplars on emotions. For example, McKinley and Fahmy (2011) 
found effects of graphicness on viewers' emotions — a finding consistent with that of Grizzard and colleagues (2015). Our failure to replicate this effect is also inconsistent with components of the MIME that are based on exemplification theory. One interpretation of this observation is that exemplar strength (i.e., concreteness) does not play a role in an exemplar's ability to increase the salience of an intuition. However, given the findings by both Grizzard et al. (2015) and McKinley and Fahmy (2011) regarding emotional reactions, this interpretation seems rather implausible. Another interpretation is that our stimuli did not vary exemplar strength effectively. Although these are both possibilities, we think a third possibility might account for the failure to find an effect of this factor: We conducted our research only two weeks after the Paris attacks, and at this time it did not take a very strong stimulus to strengthen the emotional impact of the news story and increase the salience of related moral intuitions. Reports from participants suggest that the events were not far from their thoughts before exposure to our stimuli, and many reported that they recently read and thought about the events in the news. As such, any stimulus showing news of the Paris terrorist attacks (i.e., whether high or low in concreteness) may have been powerful enough to fully activate intuitions related to the events. Evidence of this is apparent in our manipulation check for exemplar strength, which showed that although the high and low conditions varied as expected in perceived concreteness, they did not vary in emotionality.

The likelihood that any other news story on the Paris attacks than the ones we used would have activated the authority intuition and altered behavioral intention is supported by the fact that terrorist news exposure did affect intuition salience and subsequent behavioral intentions across the combined exemplar strength conditions. Our data suggest that the story was a powerful (i.e., emotional) exemplar at both levels of our exemplar strength manipulation, and as such was able to affect the salience of moral intuitions as measured by the MFQ. It is worth noting that the materials used to create the Paris attack news stimuli focused on the attack and not on the suffering of victims. It is possible that stimuli focusing more on 
victimization would have affected the salience of other intuitions such as care or perhaps even fairness. Such a finding would be consistent with previous research by AUTHOR showing the ability of exposure to news stories on tornado victims to increase the salience of care.

\section{Limitations}

Several limitations are worth mentioning. In terms of individualizing intuitions, the observation that terrorist news exposure did not affect the salience of care or fairness shows that these intuitions differed from the authority and purity intuitions. Perhaps this was because the news story focused on the attack of the terrorists, and not on the suffering of the victims.

The focus on attacks may have directed the attention of audience members to feelings of threat instead of feelings of compassion for others, but this is speculation.

There is also a natural confound in our manipulation of exemplar strength. We selected images from the high strength video stimuli for use in the low strength still images condition. Although we believe that this is a reasonable manipulation of exemplar strength, the selection of certain images naturally excludes other images. If included, these images could have feasibly reduced emotionality in our low strength condition. Although it is possible that this limitation caused our failure to find differences between the high and low exemplar strength conditions, we think the recency explanation above is more likely. It seems more probable that excluded images would have increased emotionality. As such, we feel the lack of differences between our high and low exemplar strength conditions in emotionality was likely due to recency.

Finally, in addition to potential stimulus limitations, the self-report measure of intuition salience used in our study is a concern. The MFQ is a scale widely used to assess moral intuitions, which was our principal reason for its inclusion in the present study. As noted above, however, the indicators used to measure ingroup loyalty do not include items assessing bias against outgroup members. Although this may have been an intentional decision by the scale developers, who label the measure "ingroup", this feature seems to ignore the outgroup distrust component of the broader conception of ingroup loyalty found in previous MFT literature 
(Haidt \& Graham, 2007). Moreover, for our purposes, the scale limits its comparability to prior research examining outgroup bias (e.g., Das et al., 2009).

Given these limitations and the fact that our study is one of the first to test the mediation process outlined in MIME in the context of terrorist news the findings of this study have to be treated very cautiously. Future research is advised to replicate the study in order to further empirically underpin the MIME's theoretical predictions.

\section{Conclusion}

Our study attempted to examine the impact of a single exposure to terrorist attack news on the salience of moral intuitions and outgroup prejudice. Our findings demonstrated its ability to increase the salience of the authority intuition, which in turn decreased the willingness to help outgroup members. This observation raises important questions regarding the ability of terrorist attack news to impact the authority intuition and the mechanisms associated with it. Future research is needed not only to replicate the short-term findings of the current study, but to investigate the potential long-term processes. Is heavy exposure to news of terrorist attacks positively related to the chronic salience of the authority intuition? Is the chronic salience of the authority intuition negatively related to support for outgroup members, or other related outcomes not examined in the current study, such as voting behaviors, the support for extremist groups, or the committing of hate crimes?

We began our study by arguing that consideration of intuitive motivations could add to understandings of the way exposure to terrorist news can influence explicit attitudes and social prejudice. While extensive research examines media's impact on attitudes, less attention has been paid to fundamental underlying instincts upon which specific attitudes are based. The findings here suggest the potential value of the MIME for explicating mechanisms through which media exposure can influence tolerance for other people and ideas. However, this is only an initial attempt to apply the MIME to this area of research, and considerable work is needed before we can be confident in its value to understanding the impact of terrorist attack news. 


\section{References}

\section{AUTHOR}

Alderman, L., \& Ardley, J. (2015, November 13). Paris terror attacks leave awful realization: Another massacre. New York Times. Retrieved from http://www.nytimes.com/2015/11/14/world/europe/paris-terror-attack.html?_r=0

Althaus, S. L. (2002). American news consumption during times of national crisis. PS:

Political Science \& Politics, 35, 517-521. doi:10.1017/S104909650200077X

Boomgaarden, H. G., \& De Vreese, C. H. (2007). Dramatic real-world events and public opinion dynamics: Media coverage and its impact on public reactions to an assassination. International Journal of Public Opinion Research, 19, 354-366. doi:10.1093/ijpor/edm012

Bozzoli, C., \& Müller, C. (2011). Perceptions and attitudes following a terrorist shock: Evidence from the UK. European Journal of Political Economy, 27, S89-S106. https://doi.org/10.1016/j.ejpoleco.2011.06.005

Das, E., Bushman, B. J., Bezemer, M. D., Kerkhof, P., \& Vermeulen, I. E. (2009). How terrorism news reports increase prejudice against outgroups: A terror management account. Journal of Experimental Social Psychology, 45, 453-459. doi:10.1016/j.jesp.2008.12.001

Echebarria-Echabe, A., \& Fernández-Guede, E. (2006). Effects of terrorism on attitudes and ideological orientation. European Journal of Social Psychology, 36, 259-265. doi:10.1002/ejsp.294

Florian, V., \& Mikulincer, M. (1997). Fear of death and the judgment of social transgressions: a multidimensional test of terror management theory. Journal of Personality and Social Psychology, 73(2), 369-380.

doi: 10.1037/0022-3514.73.2.369

Graham, J., Haidt, J., \& Nosek, B. A. (2009). Liberals and conservatives rely on different sets of moral foundations. Journal of Personality and Social Psychology, 96, 1029-1046. doi: $10.1037 / \mathrm{a} 0015141$ 
Graham, J., Nosek, B. A., Haidt, J., Iyer, R., Koleva, S., \& Ditto, P. H. (2011). Mapping the moral domain. Journal of Personality and Social Psychology, 101, 366-385. doi: $10.1037 / \mathrm{a} 0021847$

Greenberg, J. (1987). The college sophomore as guinea pig: Setting the record straight. The Academy of Management Review, 12, 157-159. Retrieved from http://www.jstor.org/stable/258001

Greenberg, J., Pyszczynski, T. \& Solomon, S. (1986). The causes and consequences of a need for self-esteem: A terror management theory. In R.F. Baumeister (Ed.), Public and private self (pp. 189-212). New York: NY, Springer-Verlag.

Grizzard, M., Plante, A. H., Huang, J., Weiss, J., Novotny, E., \& Ngho, Z. (2015, November). Graphic violence as moral motivator: Viewing atrocities makes us morally sensitive. Paper presented at the Annual Conference of the National Communication Association, Las Vegas, NV.

Haidt, J., \& Graham, J. (2007). When morality opposes justice: Conservatives have moral intuitions that liberals may not recognize. Social Justice Research, 20, 98-116. doi:10.1007/s11211-007-0034-Z

Haidt, J., \& Joseph, C. (2007). The moral mind: How five sets of innate intuitions guide the development of many culture specific virtues, and perhaps even modules. In P. Carruthers, S. Laurence, \& S. P. Stich (Eds.), Evolution and cognition. The innate mind (pp. 367-392). New York: Oxford University Press.

Hetherington, M., \& Suhay, E. (2011). Authoritarianism, threat, and americans' support for the war on terror. American Journal of Political Science, 55, 546-560. doi:10.1111/j.15405907.2011.00514.x

Kohlberg, L., Levine, C., \& Hewer, A. (1983). Moral stages: A current formulation and a response to critics ; 9 tables. Contributions to human development: Vol. 10. Basel: Karger. 
Kugler, M., Jost, J. T., \& Noorbaloochi, S. (2014). Another look at moral foundations theory:

Do authoritarianism and social dominance orientation explain liberal-conservative

differences in "moral" intuitions? Social Justice Research, 27, 413-431.

doi:10.1007/s11211-014-0223-5

McKinley, C. J., \& Fahmy, S. (2011). Passing the "Breakfast Test": Exploring the Effects of Varying Degrees of Graphicness of War Photography in the New Media Environment. Visual Communication Quarterly, 18(2), 70-83. doi:10.1080/15551393.2011.574060

Leach, C. W., Van Zomeren, M., Zebel, S., Vliek, M. L. W., Pennekamp, S. F., Doosje, B., et al (2008).Group-level self-definition and self investment: A hierarchical (multi-component) model of in-group Identification. Journal of Personality and Social Psychology, 95, 144 165.

Mogensen, K. (2008). Television journalism during terror attacks. Media, War \& Conflict, 1, 31-49. doi:10.1177/1750635207087624

Simons, R. F., Detenber, B. H., Roedema, T. M., \& Reiss, J. E. (1999). Emotion processing in three systems: The Medium and the message. Psychophysiology, 36, 619-627.

Tamborini, R. (2011). Moral intuition and media entertainment. Journal of Media Psychology: Theories, Methods, and Applications, 23, 39-45. doi:10.1027/1864-1105/a000031

Tamborini, R. (2013). A model of intuitive morality and exemplars. In R. C. Tamborini (Ed.), Media and the moral mind (pp. 43-74). Abingdon, Oxon, New York, NY: Routledge.

Tamborini, R., Prabhu, S., Lewis, R. J., Grizzard, M., \& Eden, A. (2016). The influence of media exposure on the accessibility of moral intuitions and associated affect. Journal of Media Psychology, 1-12. https://doi.org/10.1027/1864-1105/a000183

Traugott, M., Brader, T., Coral, D., Curtin, R., Featherman, D., Groves, R., Hill, M., Jackson, J., Juster, T., Kahn, R., Kennedy, C., Kinder, D., Pennell, B.-E., Shapiro, M., Tessler, M. Weir, D., Willis, R. (2002). How Americans Responded: A Study of Public Reactions to 9/11/01. PS: Political Science \& Politics, 35, 511-516. doi:10.1017/S1049096502000768 
van Leeuwen, F., \& Park, J. H. (2009). Perceptions of social dangers, moral foundations, and political orientation. Personality and Individual Differences, 47, 169-173. doi:10.1016/j.paid.2009.02.017

Zillmann, D. (2002). Exemplification theory of media influence. In J. Bryant \& D. Zillmann (Eds.), Media effects. Advances in theory and research (2nd ed., pp. 19-41). Mahwah, NJ: Erlbaum.

Zillmann, D., \& Brosius, H.-B. (2000). Exemplification in communication: The influence of case reports on the perception of issues. Communication theory and methodology. Mahwah, N.J: Erlbaum Assoc. 


\section{Notes}

${ }^{1}$ It is possible that the salience of individualizing intuitions (care and fairness) could mediate the influence of exposure to media exemplars on behavior in much the same way as predicted in our model with binding intuitions. However, inconsistencies in previous research relating exposure to terrorist attack news to individualizing intuitions make expectations for this model difficult to ascertain. One could argue that concern for the victims of the attacks would make the care intuition more salient. Grizzard et al.’s (2015) findings showed that, in addition to influencing the salience of the binding intuitions, exposure to terrorist film clips also increased the salience of the more liberal, or individualizing intuitions. Conversely, other research has shown that while knowledge of terrorist attacks increases conservative and authoritarian attitudes related to the binding intuitions, it can decrease liberal attitudes related to the individualizing intuitions. For example, Bozzoli and Müller (2011) found that the 2005 London bombings significantly decreased support for civil liberties while increasing support for enhanced security. Given the contradictory findings, there are no solid grounds for a hypothesis regarding the effects of exposure to terrorist activities on individualizing moral intuitions. As such, we can make no predictions about the ability of individualizing intuitions to mediate the influence of exposure to terrorist attack news on intention to donate to outgroup members. Nevertheless, though we pose no specific hypothesis here, as described below, individualizing intuitions are measured and examined in our study.

${ }^{2}$ One important reason for using a sample of undergraduate communication students was that student samples are quite homogenous in terms of age and developmental stage. This homogeneity is important when it comes to basic research because it ensures internal validity of results (see for example, Greenberg, 1987).

${ }^{3}$ This study was deemed exempt under IRB ID\# i04990 on 10/29/15 because (1) human subjects could not be identified, directly or through identifiers linked to the subjects; and (2) disclosure of human subjects' responses outside the research could not reasonably place the 
subjects at risk of criminal or civil liability or be damaging to the subjects' financial standing, employability, or reputation. Approval occurred before the terrorist attacks. We contacted IRB to approve changes to our stimuli in an existing exempt IRB application (procedures remained the same). The IRB informed us that the changes did not alter the exempt status.

${ }^{4}$ Study 2 was conducted in order to address reviewer concerns regarding the success of our perceived group membership manipulation in our main study. We want to thank the reviewer for identifying this concern. 
Tables

Table 1.

Means, Standard Deviations, and Zero-Order Correlations

\begin{tabular}{lllllllll}
\hline & $\alpha$ & $M$ & $S D$ & 1. & 2. & 3. & 4. & 5. \\
\hline 1. Care & .63 & 4.43 & 0.70 & & & & & \\
2. Fairness & .65 & 4.29 & 0.65 & $.62^{* *}$ & & & & \\
3. Loyalty & .61 & 3.84 & 0.72 & $.25^{* *}$ & $.28^{* *}$ & & & \\
4. Authority & .56 & 4.00 & 0.67 & $.28^{* *}$ & $.28^{* *}$ & $.62 * *$ & & \\
5. Purity & .71 & 3.66 & 0.87 & $.31^{* *}$ & $.26^{* *}$ & $.52 * *$ & $.60 * *$ & \\
6. Amount donated & - & 3.65 & 4.20 & $.13^{*}$ & $.14^{*}$ & -.09 & -.11 & -.08 \\
\hline Note. $* p<.05 . * * p<.01$. & & & & & & & &
\end{tabular}

Table 2.

Moderated Mediation Model: Indirect Effect of Terrorist News (IV) on Donation Amount

Offered (DV), Mediated by Authority Salience (M) Moderated by Ingroup vs. Outgroup (Mo)

\begin{tabular}{lcccc}
\hline \multirow{2}{*}{\begin{tabular}{l} 
Predictors \\
\cline { 2 - 4 }
\end{tabular}} & \multicolumn{4}{c}{ Mediator Variable Model (DV=Authority) } \\
\hline Terrorist News $(0=$ control news) & 0.27 & 0.09 & 2.97 & .00 \\
& Model summary $R^{2}=.04, F(1,236)=8.83, p=\leq .005$ & \\
\hline
\end{tabular}

Dependent Variable Model (DV=Intended

Donation Amount)

\begin{tabular}{lcccc}
\cline { 2 - 5 } Predictors & $b$ & $S E$ & $t$-Value & $p$-Value \\
\hline Terrorist News $(0=$ control news $)$ & -2.21 & 0.84 & -2.63 & .01 \\
Authority & -1.27 & 0.60 & -2.12 & .03 \\
Ingroup vs. Outgroup $(0=$ Middle East $)$ & -7.39 & 3.27 & -2.26 & .02 \\
Authority*Ingroup vs. Outgroup & 1.42 & 0.82 & 1.74 & .08 \\
Terrorist News*Ingroup vs. Outgroup & 1.76 & 1.17 & 1.51 & .13 \\
$\quad$ Model summary $R^{2}=.06, F(5,232)=2.99, p<=.015$ &
\end{tabular}

Conditional Direct Effects of Terrorist News on

Intended Donation Amount at Values of Ingroup

vs. Outgroup

\begin{tabular}{ccccc}
\cline { 2 - 5 } Ingroup vs. Outgroup & $b$ & $S E$ & $t$-Value & $p$-Value \\
\hline Middle East & -2.21 & 0.84 & $-2.6 \underline{3} z$ & .01 \\
USA & -0.45 & 0.81 & -0.56 & .57 \\
\hline
\end{tabular}


Conditional Indirect Effects of Terrorist News on Donation at Values of Ingroup vs. Outgroup

\begin{tabular}{lcccc}
\cline { 2 - 4 } Mediator & $\begin{array}{c}\text { Ingroup vs. } \\
\text { Outgroup }\end{array}$ & $b$ & Boot $S E$ & Boot 95\% CI \\
\hline Authority & Middle East & -0.34 & 0.20 & -0.85 to -0.04 \\
Authority & USA & 0.04 & 0.17 & -0.25 to 0.43 \\
\hline
\end{tabular}

Note: $b=$ unstandardized coefficient, bootstrap samples $=5000$. 
Figures

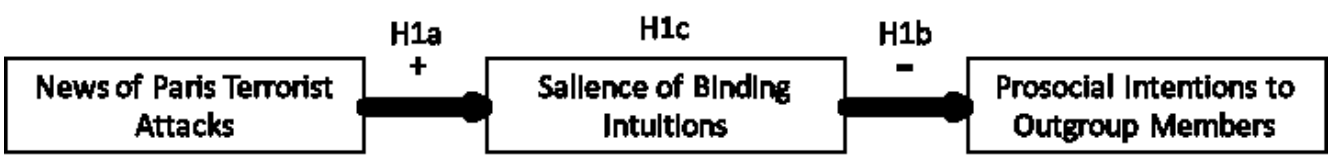

Figure 1. A mediation model that highlights the role of binding intuition salience as a mechanism through which exposure to terrorist attack news influences prosocial behavioral intentions toward outgroup members.

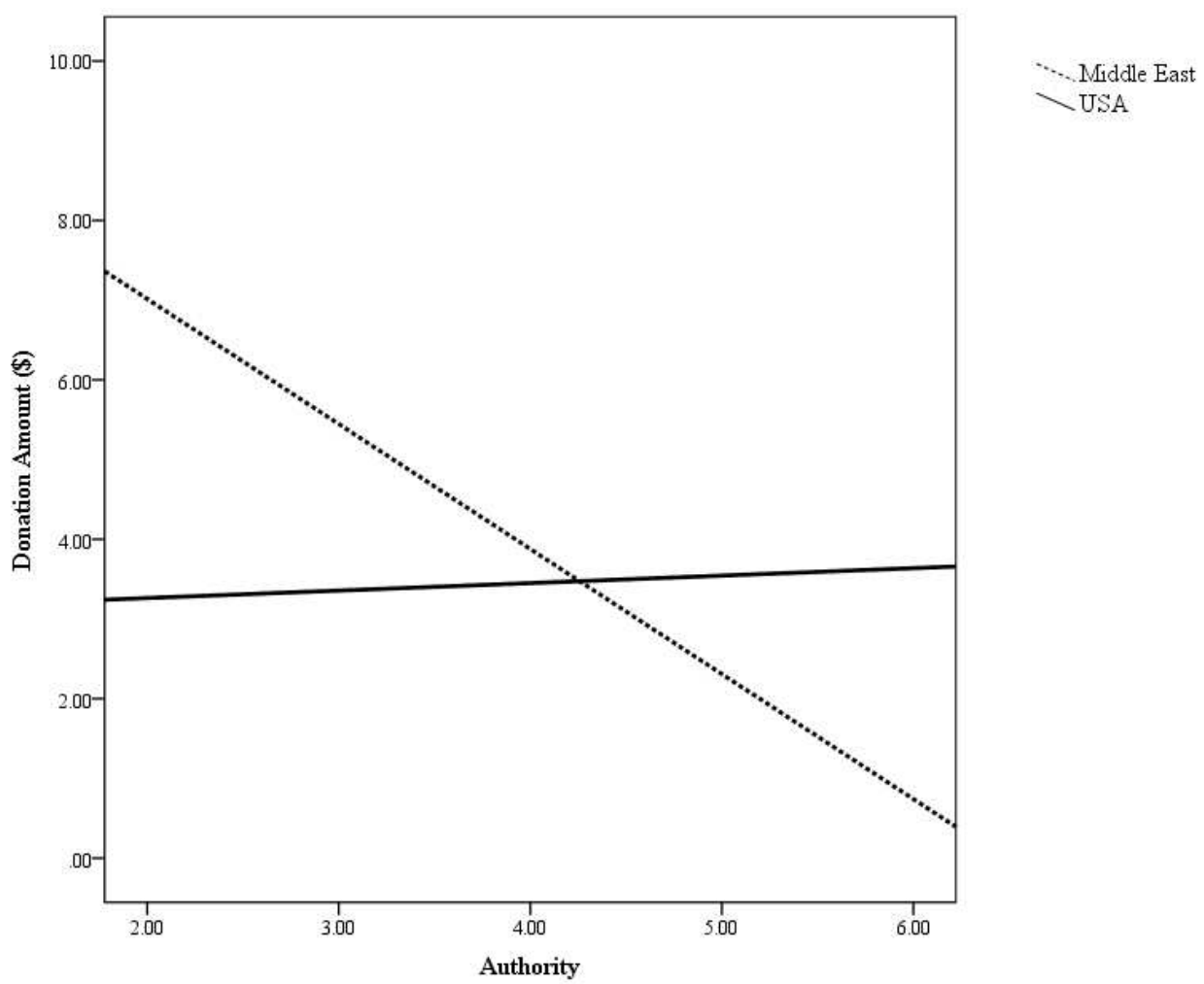

Figure 3. Interaction of Authority Intuition Salience and Donation Target on Intended

Donation Amount 